\title{
Atlanta ça rime à quoi?
}

Comme I'Atlantide engloutie

il hante les rues et les coeurs d'Atlanta

1e rejeton de I'Oncle Sam

s'amuse de ce brouhaha

tueur à gages, mercenaire

pour qui, pourquoi

te grises-tu de talents sanguinaires

au large de nos portes

et à la barbe du soleil?

Etouffe étrangle assomme

tiens-t'en à la consigne

toi qui as le bras long

ô espoirs engloutis

dans les flots de Chattahoochee ${ }^{\S}$

$\$ /$ t $\int$ tə’hu:t $\int \mathrm{i} /:$ rivière de $1 \mathrm{a}$ Géorgie occidentale. 
Atlanta

ça rime à quoi?

éternelle rengaine.

au son des mêmes tambours

c'est le Caucase ${ }^{\S}$ en rut

quelle drôle de façon

dans les flocons d'écumes d'Atlanta

flotte

une mignonne tête

hier encore une main

qui frôlait les vitrines

de ses petits doigts de dix ans

et maintenant le 1 ot

des faits et gestes peu baptistes

et encor bien moins catholiques

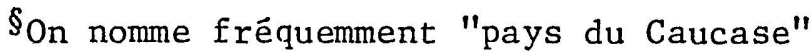
les républiques soviétiques d'Arménie, d'Azerbä̈jan et de Géorgie. Le Caucase: chaîne de montagnes de $1^{\prime}$ U.R.S.S. où de puissants volcans ont été enregistrés.

Elle flotte elle flotte elle flotte

cette main, cette bouche qui 
deux trois quatre ans d'ici

aurait gagné

à être embrassée mordue

cette main

cette bouche

a succombé

aux ides de mars

aux faits et gestes

d'une pensêe haineuse

Et quoi qu'en dise le système

pour DALTONIEN qu'il se prenne

habilité qu'il est

à tenir la dragée haute

à la plèbe minoritaire

il est temps de percer 1'ulcère

de mettre fin à ce mystère

des mômes mélanine

qui disparaissent

au fil des jours

dans la gueule écumante d'Atlanta 
au son des mêmes tambours

au son des mêmes discours

Ie Dieu chrétien se serait tu

et prêterait la sourde oréille

au dernier "Sauve qui peut"

des mômes minoritaires

qui, en tribut au Minotaure

au fil des jours,

disparaissent

dans la gueule écumante d'Atlanta.

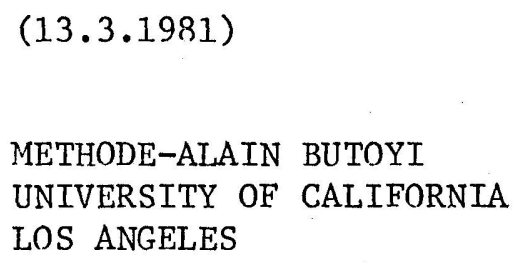

